\title{
Maize Protein Extraction for Different Downstream Applications
}

\author{
María Jazmín Abraham-Juárez ${ }^{1, \$, *}$
}

\begin{abstract}
${ }^{1}$ Department of Biology, University of Massachusetts Amherst, Amherst, MA, USA; ${ }^{\$}$ Current address: CONACYT. División de Biología Molecular, Instituto Potosino de Investigación Científica y Tecnológica (IPICYT), San Luis Potosí, SLP, Mexico

*For correspondence: maria.abraham@ipicyt.edu.mx
\end{abstract}

[Abstract] Sample preparation is a key step for making plant proteomics analyses reproducible. The large amount of organic compounds, complex polysaccharides, proteases and other cellular components in vascular plants interfere with the analysis of proteins from these organisms (Carpentier et al., 2005; Wang et al., 2008). This makes the development of suitable methods for this a challenge and makes key steps in plant protein extraction including tissue disruption, secondary metabolites removal and protein solubilization even more critical. Nonetheless, the downstream application is the most important thing that a researcher needs to consider when choosing a protein extraction method. Maize has been utilized as a model plant for developmental genetics in the grasses, and researchers working with maize have been applying molecular techniques to be able to analyze proteins in planta at similar to how proteins are analyzed in eudicot model plants. Here, I describe a simple maize protein extraction method using different extraction buffers that can be used for simple downstream applications like immunoblot as well as more complex applications like immunoprecipitation (IP). One advantage of this method is that it is very fast, so there is an increased chance of being able to analyze unstable proteins and proteins found in low abundance by immunoblot and/or IP. Another advantage of this protocol is that it does not require subcellular fractionation, which may degrade unstable and/or unabundant proteins. Depending on the downstream application to be used, this protocol is flexible and it is compatible with buffers that contain detergents and chaotropic agents which result in varying degrees of protein denaturation. In the recipes section, buffer preparation instructions go from milder conditions to more denaturing conditions. Buffers 1 and 2 are suitable for immunoprecipitation of protein complexes since they are milder buffers and many protein-protein interactions will be preserved in these buffers. Buffers 3 and 4 are suitable for immunoblot detection (Western blot) since they use ionic detergents and reducing reagents that reduce protein disulfide bonds. If the protein extract will be analyzed for the phosphorylation status of a target protein, then phosphatase inhibitor mix can be added to the recipes.

Keywords: Maize, Protein, Extraction buffer, Immunoblot

\section{Materials and Reagents}

1. $50 \mathrm{ml} \mathrm{Falcon} \mathrm{tube}$

2. Protease-free $1.5 \mathrm{ml}$ Eppendorf tubes and $35 \mathrm{ml}$ Sorvall centrifuge tubes 
3. Protease-free pipette tips $(1,000,200$ and $10 \mu \mathrm{l})$

4. $0.2-\mu \mathrm{m}$ filter

5. Plant material (leaf, shoot apical meristem, inflorescence meristem, roots, floral organs) (Figure 1 , see Note 2)

6. Liquid nitrogen

7. Tris base (Sigma, catalog number: T1503)

8. Sodium chloride (Sigma, catalog number: S7653)

9. IGEPAL-CA-630 (Sigma, catalog number: I8896)

10. Complete ${ }^{\mathrm{TM}}$ Protease Inhibitor Cocktail tablets (Sigma, catalog number: 11697498001)

11. PhosSTOPTM Phosphatase inhibitor tablets (Sigma, catalog number: 4906845001)

12. DL Dithiothreitol (Sigma, catalog number: 43819)

13. Sucrose

14. Glycerol

15. EDTA, Disodium Salt, Dihydrate (Sigma, catalog number: 324503)

16. Magnesium chloride (Sigma, catalog number: M8266)

17. $\beta$-mercaptoethanol (Sigma, catalog number: M6250)

18. Sodium dodecyl sulfate, SDS (Sigma, catalog number: 436143)

19. Bromophenol blue (Bio-Rad, catalog number: 1610404)

20. Pierce $660 \mathrm{~nm}$ protein assay kit (Thermo Fisher Scientific)

21. GelCode Blue Safe Protein Stain (Thermo Scientific)

22. Buffer 1 (see Recipes)

23. Buffer 2 (see Recipes)

24. Buffer 3 (see Recipes)

25. Buffer 4 (see Recipes)

26. 25x Protease inhibitor mix (see Recipes)

27. 10x Phosphatase inhibitor (PhosSTOP) mix (see Recipes)

\section{Equipment}

1. Pipettes

2. Sterile mortar and pestle

3. Spatula

4. $-80{ }^{\circ} \mathrm{C}$ freezer

5. Refrigerated centrifuge

6. Vortex homogenizer

7. Spectrophotometer

8. Incubator 


\section{Procedure}

1. After sectioning the plants, collect the plant tissue by immediately freezing in liquid nitrogen. Keep the tissue frozen until use. Use a $1.5 \mathrm{ml}$ Eppendorf tube if you are collecting $100 \mathrm{mg}$ to $500 \mathrm{mg}$ of tissue, which is enough for immunoblot (100 mg of tissue is usually around $200 \mu \mathrm{l}$ volume). Use a $50 \mathrm{ml}$ Falcon tube if you are collecting 5 to $10 \mathrm{~g}$ of tissue, for IP (see Note 1).

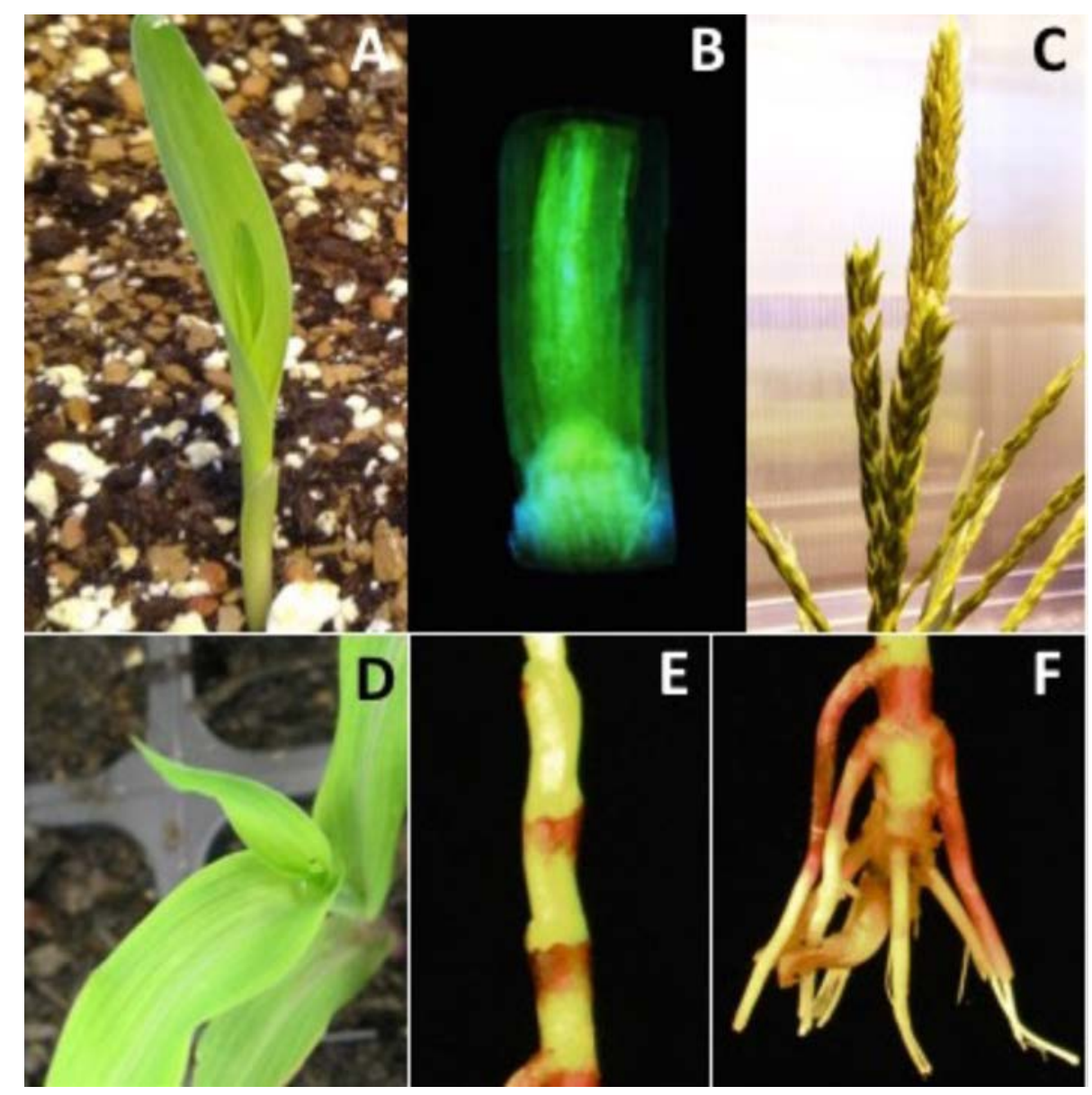

Figure 1. Examples of tissue samples that can be used in this protocol. A. Seedling. B. Shoot apical meristem with leaves. C. Mature tassel. D. Leaf. E. Stem. F. Root.

2. Grind plant material in liquid nitrogen with a mortar and pestle until it is completely homogenized. If an immunoblot is going to be performed, then grind $100 \mathrm{mg}$ of plant material then use a spatula (that was previously frozen in liquid Nitrogen) to transfer the powder to a clean $1.5 \mathrm{ml}$ Eppendorf tube. If an IP is going to be performed, then grind 3-5 $\mathrm{g}$ of plant material then add it to a $35 \mathrm{ml}$ Sorvall centrifuge tube. Complete homogeneity is very important to get enough yield and reproducibility between samples. Be careful not to let the tissue powder thaw before transferring to the Eppendorf tube or to the Sorvall centrifuge tube.

3. Add $2 x$ volume of plant material ( $200 \mu$ for $100 \mathrm{mg}$ of tissue) of ice cold extraction buffer and homogenize immediately by vortexing for $10 \mathrm{~s}$, to avoid sample degradation. 
Notes:

a. Prepare the extraction buffer on the same day, right before it is needed. In our experience, fresh buffer yields the best results. The volume of extraction buffer needed depends on the amount of tissue and number of samples to be processed.

b. It is critical to keep the samples on ice after defrosting and centrifuge at $4{ }^{\circ} \mathrm{C}$, to avoid protein degradation.

4. Incubate the homogenate on ice for $10 \mathrm{~min}$, mix by inverting five times at $5 \mathrm{~min}$ of start incubation.

5. Centrifuge at $15,000 \times g$ for 10 min at $4{ }^{\circ} \mathrm{C}$.

6. Transfer supernatant (protein extract) to a new tube and keep on ice for immediate use, or snap freeze small aliquots (30 $\mu \mathrm{l}$ for immunoblot) in dry ice or liquid nitrogen and store at $-80{ }^{\circ} \mathrm{C}$. For quantitation, immediately mix with Pierce $660 \mathrm{~nm}$ protein assay solution then determine the protein concentration using a spectrophotometer or plate reader, or use the quantitation method you prefer. For immunoblot, mix with loading buffer at $1 x$ final concentration to carry out SDSPAGE (Figure 2).

Notes:

a. The ratio of protein extract: cell debris will be different for each kind of tissue. For example, the ratio is smaller for tissues with low water content, such as old leaves and starchy stems.

b. To get the best results in downstream applications, store the plant tissue at $-80^{\circ} \mathrm{C}$ and make fresh protein extract each time it is needed. For IP it is necessary to use a fresh protein extract. For immunoblot small aliquots may be stored at $-80^{\circ} \mathrm{C}$, when the protein to be detected is abundant. But when the protein is unstable and not abundant, it is better to prepare a fresh protein extract. 


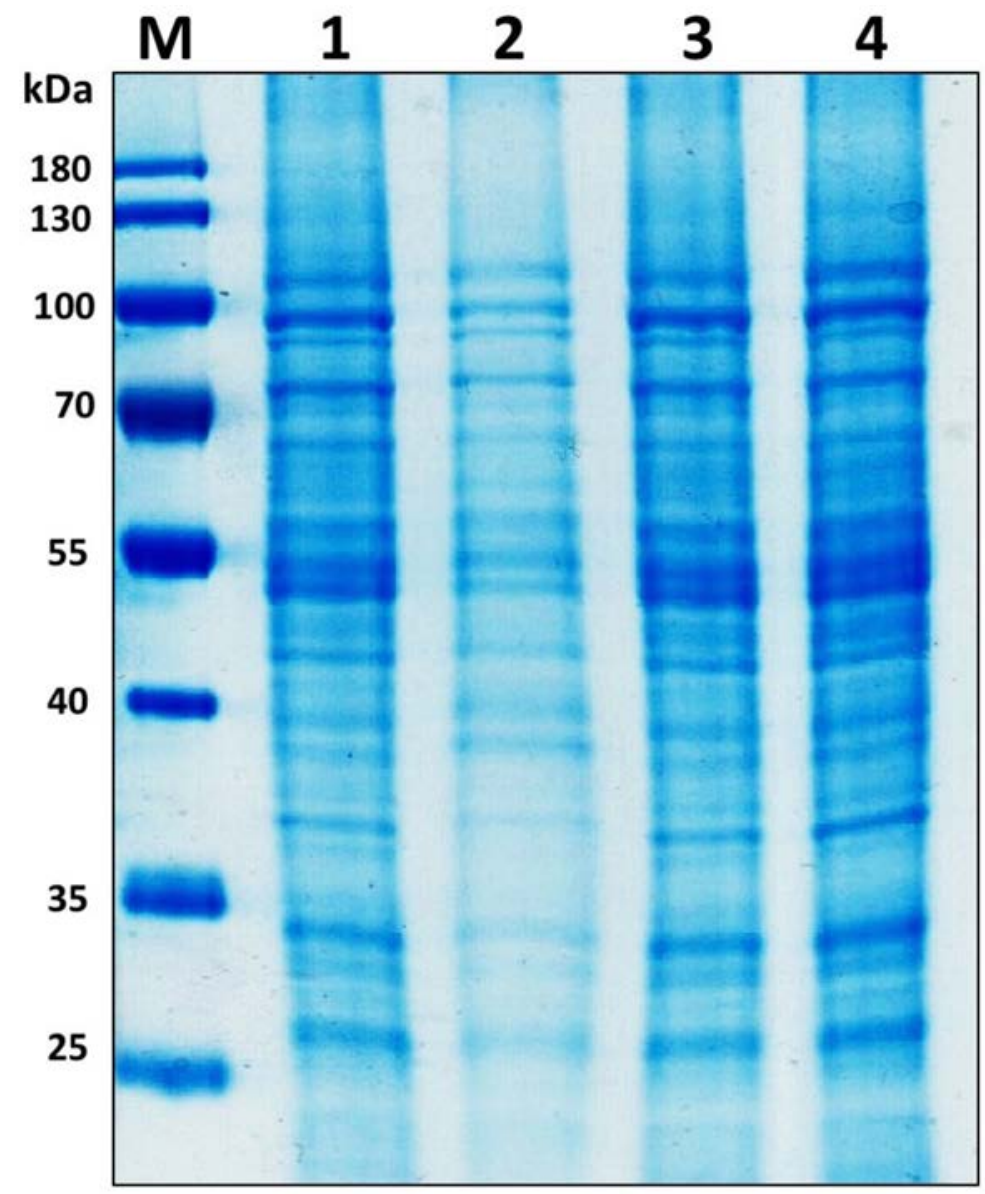

Figure 2. Analysis of total maize protein extracted using the Buffers 1-4 (see Recipes section for buffer details). One hundred milligrams of shoot apices including $0.5 \mathrm{~cm}$ of leaf base (Figure 1B) were used for extraction. Twenty micrograms of protein was loaded in each well of a 12\% sodium dodecyl sulfate-polyacrylamide gel electrophoresis (SDS-PAGE) gel. Following electrophoresis, the gel was stained using GelCode Blue Safe Protein Stain (Thermo Scientific).

\section{Notes}

1. This protocol may be scaled up to get enough protein for many downstream applications. 100 $\mathrm{mg}$ of tissue is enough to get at least $100 \mu \mathrm{l}$ of protein extract, but the concentration will depend on the tissue used. For immunoblot, usually 10 to $15 \mu \mathrm{l}$ (or $20 \mu \mathrm{g}$ of protein) of extract is enough. For immunoprecipitation, 3 to $5 \mathrm{~g}$ of tissue are commonly used, depending on the expression level of the protein of interest.

2. Using different tissues will affect the yield of protein. In general, more protein is extracted from meristematic tissue (shoot apical meristem, inflorescence meristem, root meristem, floral organ primordia). And less protein will be extracted from highly differentiated tissue (leaf, mature floral organ, lignified roots). 


\section{Recipes}

Notes:

a. It is important to prepare all the solutions using MilliQ water, new protease-free tubes and filter the final solution stock through a $0.2 \mu \mathrm{m}$ filter.

b. Protease Inhibitor mix (Recipe 5) and Phosphatase inhibitor (PhosSTOP) mix stocks (Recipe 6) may be stored at $-20^{\circ} \mathrm{C}$ for two weeks.

1. Buffer 1

Protein Extraction buffer for proteins dynamically transported between nucleus and cytosol, in native conditions (modified from Smaczniak et al., 2012).

$50 \mathrm{mM}$ Tris- $\mathrm{HCl}(\mathrm{pH} 7.5)$

$150 \mathrm{mM} \mathrm{NaCl}$

1\% IGEPAL-CA-630

$2 x$ protease inhibitor mix

2. Buffer 2

Protein Extraction buffer for membrane-localized proteins, in native conditions (modified from Smaczniak et al., 2012).

$50 \mathrm{mM}$ Tris- $\mathrm{HCl}(\mathrm{pH} 7.5)$

$150 \mathrm{mM} \mathrm{NaCl}$

2\% IGEPAL-CA-630

2x protease inhibitor mix

3. Buffer 3

Total protein extraction buffer for immunoblot, partially denaturing conditions (modified from Hennig and Köhler, 2010).

$100 \mathrm{mM}$ Tris $\mathrm{pH} 7.2$

$10 \%$ sucrose

$5 \mathrm{mM} \mathrm{MgCl}_{2}$

5 mM EDTA

$40 \mu \mathrm{M} \beta$-mercaptoethanol, protease inhibitor cocktail

$1 \%$ IGEPAL-CA-630

$0.1 \%$ SDS

4. Buffer 4

Total protein extraction buffer for very low abundant membrane localized proteins, for immunoblot, denaturing conditions (Rosa et al., 2017).

$0.25 \mathrm{M}$ Tris- $\mathrm{HCl}(\mathrm{pH} 6.8)$

$0.5 \mathrm{M}$ Dithiothreitol

$50 \%$ glycerol

$10 \%$ SDS 
$0.25 \%$ bromophenol blue

5. 25x Protease inhibitor mix

Dissolve 1 tablet in $2 \mathrm{ml}$ of $\mathrm{MQ}$ water

For use, dilute at $1 x$ final concentration in the extraction buffer

6. 10x Phosphatase inhibitor (PhosSTOP) mix

Dissolve 1 tablet in $1 \mathrm{ml}$ of MQ water

For use, dilute at $1 x$ final concentration in the extraction buffer

\section{Acknowledgments}

MJAJ was supported by UC-MEXUS CONACYT and by NSF IOS-1238202 at Dr. Sarah Hake Lab, where this protocol was developed. I would like to thank Dr. Sarah Hake and Dr. Madelaine Bartlett for their continuing scientific support. I declare no conflict of interest regarding the implementation of this protocol.

\section{References}

1. Carpentier, S. C., Witters, E., Laukens, K., Deckers, P., Swennen, R. and Panis, B. (2005). Preparation of protein extracts from recalcitrant plant tissues: an evaluation of different methods for two-dimensional gel electrophoresis analysis. Proteomics 5: 2497-2507.

2. Hennig, L. and Köhler, C. (2010). Plant developmental biology methods and protocols. Department of Biology, Swiss Federal Institute of Technology (ETH), Humana Press, Zurich, Springer. P352.

3. Rosa, M., Abraham-Juarez, M. J., Lewis, M. W., Fonseca, J. P., Tian, W., Ramirez, V., Luan, S., Pauly, M. and Hake, S. (2017). The maize MID-COMPLEMENTING ACTIVITY Homolog CELL NUMBER REGULATOR13/NARROW ODD DWARF coordinates organ growth and tissue patterning. Plant Cell 29(3): 474-490.

4. Smaczniak, C., Li, N., Boeren, S., America, T., van Dongen, W., Goerdayal, S. S., de Vries, S., Angenent, G. C. and Kaufmann, K. (2012). Proteomics-based identification of low-abundance signaling and regulatory protein complexes in native plant tissues. Nat Protoc 7(12): 2144-2158.

5. Wang, W., Tai, F. and Chen, S. (2008). Optimizing protein extraction from plant tissues for enhanced proteomics analysis. J Sep Sci 31: 2032-2039. 